\title{
Off-Pump Repair of a Post-Infarct Ventricular Septal Defect: How Safe Is the Hamburger Procedure With Oximetry Guidance?
}

\author{
Harris Georgiou ${ }^{\mathrm{a}}$, Vasileios Patris ${ }^{\mathrm{a}, \mathrm{e}}, \mathrm{Niki}_{\text {Lama }}^{\mathrm{b}}$, Orestis Argiriou ${ }^{\mathrm{c}}$, Agni Salem$^{\mathrm{d}}$, \\ Mihalis Argiriou ${ }^{\mathrm{a}}$
}

\begin{abstract}
We are reporting an off-pump technique for the surgical closure of a post-infarct ventricular septal defect (VSD). Our case report describes the case management of a 75-year-old man, who underwent the Hamburger procedure for the closure of his apical VSD. We are showing that oximetric guided off-pump posterior-anterior septal plication is a safe and effective method for closing post-infarct VSD in hemodynamically unstable patients in the absence of TOE.
\end{abstract}

Keywords: Post-infarct ventricular septal defect; Hamburger procedure; Oximetry; Guidance

\section{Introduction}

Ventricular septal defect (VSD) is an infrequent mechanical but portentous complication following myocardial infarction. VSD was first described by Latham in $1846[1,2]$; it is known to develop in approximately $1 \%$ of cardiac arrest survivors after acute myocardial infarction (AMI) [3] and generally occurs 1 week after the acute event [4]. Medical management alone is lacking and surgical intervention is usually the only option. Assorted guidelines for surgical techniques have been described, requiring the use of cardiopulmonary bypass (CPB). The 30-day mortality ranges from $23 \%$ to $42 \%$ [5-7]. The development of shock is the most important predictor of mortality. Persistence of class IV cardiogenic shock in VSD is associated with $100 \%$ mortality [8]. VSD, characterized by hemodynamic compromise, is treated by intra-aortic balloon pump (IABP) followed by early surgical repair [9].

Manuscript accepted for publication March 24, 2016

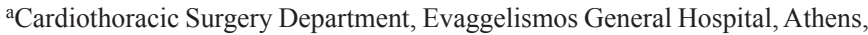
Greece

${ }^{b}$ Radiology Department, Konstantopouleio General Hospital, Athens, Greece

'York Teaching Hospital NHS Foundation Trust, York, UK

dUniversity of Liverpool School of Medicine, Liverpool, UK

${ }^{\mathrm{e} C}$ Corresponding Author: Vasileios Patris, Martinegou 44-48 N.Filothei, Athens, Greece. Email: vaspatris@gmail.com

doi: http://dx.doi.org/10.14740/jmc2476w
Recently, an off-pump closure technique called the Hamburger procedure was performed as an alternative to open procedures that require $\mathrm{CPB}$ and ventriculotomy [10].

The aims of our presenting case were to describe how a post-infarct VSD may be repaired without CPB and to highlight the importance of shunt measurement using oximetric methods for VSD closure in the absence of TOE.

\section{Case Report}

A 75-year-old patient arrived at a province hospital with an AMI and was treated with thrombolysis. Two hours after his admission to the cardiology unit, the patient suffered cardiac arrest and cardiopulmonary resuscitation was performed for 30 min. He was transported to the intensive care unit (ICU) and intubated for further management of his condition. During his hospital admission, he underwent angiography, which showed a distally occluded left anterior descending (LAD) artery and rest coronary arteries with no critical stenosis.

A week later, it was noted that he had a pansystolic murmur and transthoracic echocardiography (TTE) using a Vivid 7 Pro confirmed a $2.5 \mathrm{~cm}$ antero-apical VSD, an akinetic ventricular apex, Qp/Qs 6.33, and an ejection fraction of $20 \%$. Because of agitation upon awakening, the patient underwent a brain CT, which showed an ischemic shock, however, without neurological semiotics.

To manage his hemodynamic instability, inotropes were added, an IABP was inserted and diuretics and nitrates were commenced. Due to deterioration, 2 weeks after his admission, the patient underwent an off-pump Hamburger post-infarct VSD repair in an emergency base and in the absence of TOE (as the only TOE was out for repair), under the guidance of oximetry measurements.

VSD closure was assessed using the ratio of the volume of pulmonary flow (Qp) and systemic flow (Qs) for shunt quantification.

In our case, before intervention, the aortic blood oxygen saturation was $99 \%$, mixed venous blood oxygen saturation was $61 \%$, the left atrial blood oxygen saturation was $99 \%$, and the pulmonary artery blood oxygen saturation was $92 \%$. The ratio $\mathrm{Qp} / \mathrm{Qs}$ was approximately 6.33.

After median sternotomy, the heart was approached in order to perform a posterior-anterior septal plication in the use of 


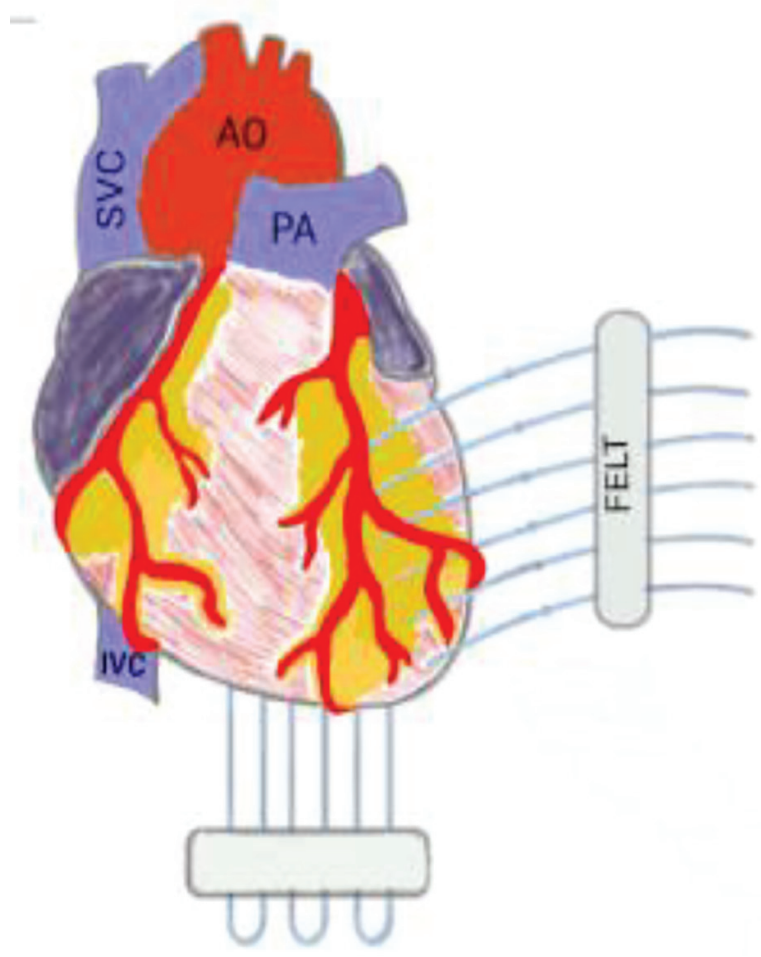

Figure 1. Diagram of the heart demonstrating suture position for the Hamburger procedure. AO: aorta; PA: pulmonary artery; SVC: superior vena cava; IVC: inferior vena cava.

four double-armed teflon felt sutures.

The teflon strip was preloaded with sutures; then, starting from above and aiming for the anterior part of the septum, the needles were passed through the posterior (inferior) interventricular septum and then through the second teflon and back again where they were tied smoothly. The sutures run close to the LAD to ensure plication of the thicker left ventricular wall [5] (Figs. 1-3).

During intervention, new oximetric measurements were made showing great improvement in the shunt size as flow ra-

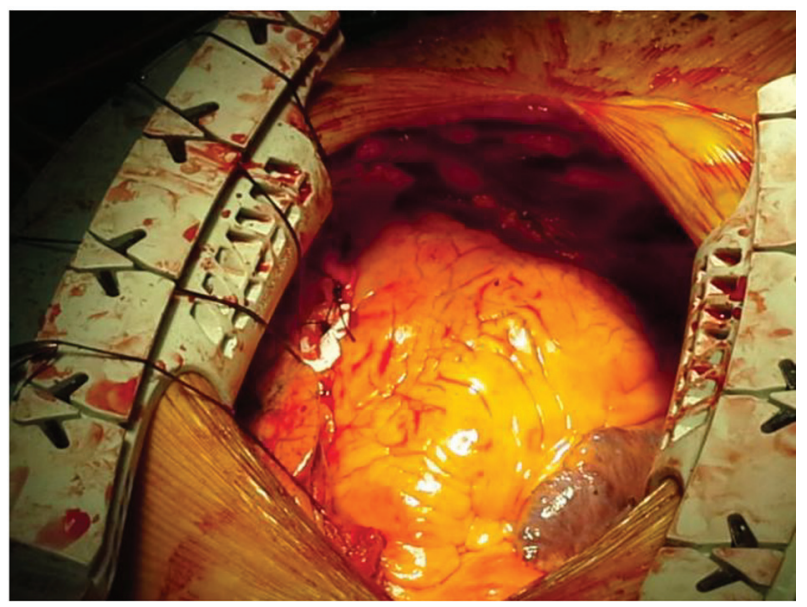

Figure 2. Sutures running just lateral to the LAD.

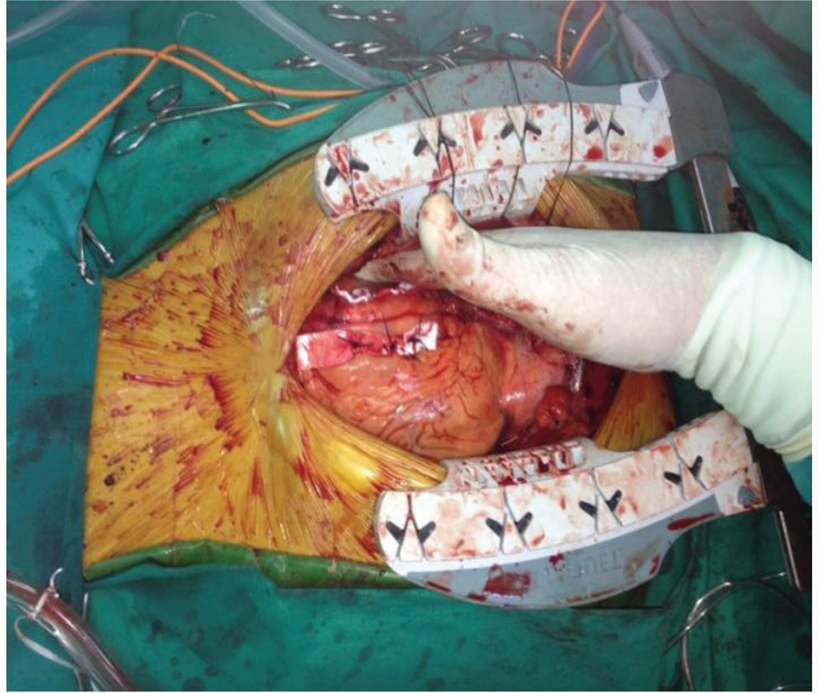

Figure 3. Needles through the teflon strip.

tio Qp/Qs was less than 2.0 after the last sutures were made.

Soon after surgery, the patient began to improve and his inotropes were discontinued. During his 1-month follow-up, the patient was found to be asymptomatic and mobilizing independently. A year later, the follow-up showed the patient to be well and a defibrillator was inserted according to the guidelines.

\section{Discussion}

During intervention, new oximetric measurements were made showing great improvement in the shunt size as flow ratio Qp/ Qs was less than 2.0 after the last sutures were made, which results from the following $\mathrm{Qp} / \mathrm{Qs}=($ SatAO - SatMV $) /($ SatLA - SatPA $)=(99-70) /(99-84)=1.93$.

Normally, this ratio is 1 as the volume of blood that is pumped to the lungs $(\mathrm{Qp})$ is equal to the volume of blood that is pumped to the body (Qs). In patients with left-to-right shunts, the Qp/Qs ratio is greater than 1. In general, a $\mathrm{Qp} / \mathrm{Qs}$ ratio of 1.5 or less is considered a small shunt; a $\mathrm{Qp} / \mathrm{Qs}$ ratio of 1.5 - 2.0 is considered a moderate shunt; and a Qp/Qs ratio of more than 2 is considered a large shunt. The $\mathrm{Qp} / \mathrm{Qs}$ ratio can be calculated if the blood oxygen saturation is known for the mixed venous return, pulmonary artery, left atrium, and aorta. The formula is $\mathrm{Qp} / \mathrm{Qs}=($ SatAO - SatMV $) /($ SatLA - SatPA $)$, where SatAO is the aortic blood oxygen saturation, SatMV is the mixed venous blood oxygen saturation, SatLA is the left atrial blood oxygen saturation, and SatPA is the pulmonary artery blood oxygen saturation.

\section{Conclusion}

The Hamburger procedure was a competent method for the repair of a post-infarct VSD. By bringing the two ventricles close using teflon supported plication sutures, the defect al- 
most vanished.

As the Hamburger procedure is a short time off-pump technique, potential sequelae of $\mathrm{CPB}$ were eliminated. As the urgent treatment of this patient was of paramount importance, the use of this procedure proved to be more beneficial compared to the alternative longer, more complex open patch repair requiring $\mathrm{CPB}$ and ventriculotomy.

Although the right way is to repair the VSD under CPB and under TOE to exclude residual shunt, in this case, we attest the importance of the use of oximetry in the absence of TOE in guiding VSD closure when the Hamburger procedure is utilized. Extra sutures were added to the initial ones under the guidance of oximetric measurements so as to ensure that a satisfactory closure was achieved. Several days later, TTE was used in the post-operative period in order to show that there was no residual VSD prior to discharge.

The Hamburger procedure is a useful alternative method for antero-apical post-infarct VSD repair. In this particularly unstable case, the Hamburger procedure proved to be the best choice, so it may be an accepted, useful and valuable technique in similar cases.

\section{References}

1. Coskun KO, Coskun ST, Popov AF, Hinz J, Schmitto JD, Bockhorst K, Stich KM, et al. Experiences with surgical treatment of ventricle septal defect as a post infarction complication. J Cardiothorac Surg. 2009;4:3.

2. Latham PM, editor: Lectures on subjects connected with clini- cal medicine, comprising diseases of the heart. Volume 2. London: Longmans, Brown, Green, and Longmans :168-176. 1845-1846.
3. Mullasari AS, Umesan CV, Krishnan U, Srinivasan S, Ravikumar M, Raghuraman H. Transcatheter closure of post-myocardial infarction ventricular septal defect with Amplatzer septal occluder. Catheter Cardiovasc Interv. 2001;54(4):484-487.

4. Di Summa M, Actis Dato GM, Centofanti P, Fortunato G, Patane F, Di Rosa E, Forsennati PG, et al. Ventricular septal rupture after a myocardial infarction: clinical features and long term survival. J Cardiovasc Surg (Torino). 1997;38(6):589-593.

5. Barker TA, Ng A, Morgan IS. Off-pump repair of a postinfarct ventricular septal defect: the 'Hamburger procedure'. J Cardiothorac Surg. 2006;1:10.

6. Labrousse L, Choukroun E, Chevalier JM, Madonna F, Robertie F, Merlico F, Coste P, et al. Surgery for post infarction ventricular septal defect (VSD): risk factors for hospital death and long term results. Eur J Cardiothorac Surg. 2002;21(4):725-731; discussion 731-722.

7. Barker TA, Ramnarine IR, Woo EB, Grayson AD, Au J, Fabri BM, Bridgewater B, et al. Repair of post-infarct ventricular septal defect with or without coronary artery bypass grafting in the northwest of England: a 5-year multi-institutional experience. Eur J Cardiothorac Surg. 2003;24(6):940-946.

8. Bolooki H. Emergency cardiac procedures in patients in cardiogenic shock due to complications of coronary artery disease. Circulation. 1989;79(6 Pt 2):I137-148.

9. 2014 ESC/EACTS Guidelines on myocardial revascularization.

10. Chikwe J, Morgan IS, Wood A. Off-Pump Repair Of Postinfarction Ventricular Septal Defect. Abstract presented at the Interna- tional Society for Minimally Invasive Cardiothoracic Surgery 8th Annual Meeting 2005. 